\section{O Medicamento como Mercadoria}

Simbólica. Fernando Lefèvre. Editora Cortez: São Paulo, Brasil, 1991. 159 p., ilustrações e bibliografia. (Brochura)

ISBN 85-249-0293-0

Cr $\$ 45.000,00$

Segundo Lefèvre, análises superficiais da questão do consumo de medicamentos tendem a focalizar a atenção em críticas ao consumo "leigo", "exagerado", "desviante". Tais análises dão ensejo ao nascimento de estratégia para a retomada de um suposto "consumo adequado", o que termina por encerrar o medicamento em sua dimensão quimioterápica, onde reina a autoridade médica. Numa ótica mais abrangente, este autor analisa o consumo de medicamentos como um problema de saúde pública per si e não enquanto uma "disfunção social", mas, ao contrário, como uma função mesmo, ou seja, como uma expressão social da hegemonia da mercadoria nas sociedades industriais contemporâneas.

Trabalhando com a questão do consumo de medicamentos, o autor descortina a mecânica do funcionamento destes como "símbolos de saúde e, através deles, a mecânica dos processos plurais e conflituosos de produção do próprio sentido de saúde. Assim, ao longo da leitura, acompanhamos o autor através de uma análise das maneiras pelas quais a saúde vem sendo historicamente expropriada de sua condição de "premissa existencial", para ser apenas recuperada, e recuperável, em um mercado de bens de consumo. Vinculada a mecanismos estruturais de ampliação e generalização do "mercado", a saúde se transforma em algo a ser obtido pelo consumo de substâncias e açōes "saudáveis", deixando de ser uma característica e um direito, para tornar-se "objeto de consumo". E neste quadro que o medicamento se apresenta como uma das materializações ou símbolos (poderosos) da saúde "biologizada" a ser consumida.

Para o autor, o entendimento da problemática ligada so consumo de medicamentos teria muito a ganhar se pudéssemos manter clareza quanto ao fato do medicamento perfazer não uma, mas pelo menos três funções articuladas: ao mesmo tempo que cura e previne (função quimioterápica), o medicamento representa e simboliza (função simbólica) e, simultaneamente, aliena e domina (função social e psicossocial).

Lefèvre trabalha com as três dimensões apontadas numa perspectiva dialética, onde o real não é dado a priori, mas constitui-se pelo esforço analítico de seu trabalho de pesquisa. A sólida base empírica para tal análise é obtida no material de entrevistas com um grupo particular de usuários de medicamentos e em textos publicitários (propagandas de medicamentos em revistas médicas, rádio, televisão, folhetos; artigos de jornais e bulas de medicamentos, entre outros).

Em conformidade com os principios da dialética, as análises realizadas são sempre posicionadas, ou seja, ao invés de postularem essências, as afirmaçōes sobre "o que é saúde" ou "o que é o medicamento" são sempre enunciadas de um determinado "ponto de vista". Tratam-se de pontos de vista gerados no funcionamento social corrente do medicamento. $O$ autor analisa, reflete, ou mesmo reconstrói tais pontos de vista, sendo capaz de representar suas vinculaçōes recíprocas e contraditórias, interrogandoos e decifrando-os como partes de um todo, de um conjunto sintético, que é a própria estrutura da sociedade de onde eles emergem. Os pontos de vista a partir dos quais Lefèvre analisa o sentido do medicamento são três; o da sociedade, o do médico e o do individuo, trabalhados, respectivamente, nos capítulos 1,2 e 3 . Para aprofundar verticalmente o sentido que os agentes sociais emprestam ao medicamento, o trabalho se apóia também na perspectiva semiótica. Esta associaçāo entre dialética e semiótica confere ao conjunto da obra uma característica muito desejada, mas nem sempre atingida, por outras análises dialéticas. Ao longo da leitura, nossa sociedade apresenta-se para o leitor não como uma estrutura cristaliza$\mathrm{da}$, mas como produto da atividade social concreta, como um processo, algo que se está criando, atualizando, dinamizando, graças às tensōes, contradiçōes e à atividade humana em seu interior.

O Capítulo 1, "o medicamento do ponto de 
vista do social", apresenta dois temas. No primeiro, "a saúde como mercadoria", o autor, através da análise de peças publicitárias, contextualiza uma visão corrente da saúde como um ente exterior do tipo mercadoria, analisando o processo de alienação decorrente desta visão, a hipertrofia da dimensão orgânica da saúde, e o conceito de necessidade de saúde.

No segundo tema, "o medicamento como mercadoria simbólica", a reflexão semiológica permite aprofundar a análise, já que a mercadoria vista enquanto um símbolo contém, como todo símbolo, uma face material (no caso dos medicamentos, grãos, comprimidos, xaropes etc.) cujo consumo permite a materialização de sua outra face, a abstrata (no caso, a saúde), ou seja, o simbolizante, ao ser consumido, realiza o simbolizado. Assim, difundir a venda da abstrata idéia de saúde torna-se fácil "embalando-a em pequenos e práticos recipientes". $O$ autor aprofunda a discussão segundo uma rede de subtemas como, por exemplo, o desejo do "valor" saúde, as relaçōes do homem com a ciência e seus produtos, e a questão da eficiência e eficácia simbólicas.

A disposição do texto em subtemas curtos facilita a assimilação das idéias desenvolvidas. Além disso, o próprio estilo de redação do autor, pautado por parágrados e frases também curtas, torna a leitura sempre muito agradável e acessível. A grande clareza com que Lefèvre expōe seu raciocínio faz com que o leitor, sem se dar conta, o acompanhe a um nivel de reflexão bastante aprofundado. Nesta obra, a arte de ensinar se reúne à escrever, fazendo com que a reflexão do autor sobre uma temática complexa não se tome, em nenhum momento, complicada ou enfadonha. Pelo contrário, a análise de Lefèvre sobre a problemática ligada ao medicamento torna esta importante discussão da saúde pública acessível a um público bem mais abrangente que o da grande maioria dos textos acadêmicos. Com isso, o autor faz mais que divulgar esta discussão, que é em si mesma fundamental; ele divulga também o método dialético e a semiótica como instrumentos de pesquisa em saúde pública, demonstrando que sua utilizaçāo não precisa necessa- riamente resultar em textos de difícil compreensão para um público leigo.

No Capítulo 2, "relações simbólicas mantidas com o medicamento pelo prescritor médico", o autor traz à tona alguns indicadores de que o médico entretem com o medicamento não apenas relações instrumentais, mas também simbólicas. Entretanto, a discussão central do capítulo relaciona-se com o processo histórico de deslocamento do poder do médico para a mercadoria, reificada "medicamento".

No Capítulo 3, "O sentido do medicamento do ponto de vista do indivíduo", Lefèvre tem nos depoimentos de um grupo de hipertensos mais uma via de acesso ao sentido do medicamento. Conforme demonstra o autor, o hipertenso, em sua vivência particular, exemplifica e ilustra características gerais sobre o sentido do medicamento do ponto de vista dos indivíduos. Elegendo como prioritárias a profundidade e a literalidade dos depoimentos dos sujeitos, o autor, que assim define essencialmente o que entende por pesquisas qualitativa, trabalha num contexto de lógica de descoberta. A análise dos depoimentos foi feita com base em temas sugeridos pela leitura dos próprios depoimentos. A lógica de descoberta é, portanto, lógica de geração de hipóteses, por oposição a um contexto de lógica de demonstração de hipóteses. Uma vez agrupados, interpretados e contextualizados, os depoimentos são apresentados segundo uma ampla rede de temas originada de sua própria análise.

$\mathrm{Na}$ última seção do livro, "Conclusões", o autor procura organizar esta temática variada soba a forma de seis eixos temáticos agregadores: 1) o medicamento e a oposição artificial $x$ natural; 2) o medicamento no contexto de uma relação de comunicação; 3) o medicamento como símbolo ambígüo de saúde e doença; 4) o medicamento e a moral: obediência e transgressão; 5) o medicamento e o desejo; eficiência e eficácia simbólicas; 6) o medicamento e a relação de consumo. Cada um dos eixos temáticos é então resumidamente descrito pelo autor, tomando seu conteúdo mais explícito e, em seguida, expresso na forma de uma hipótese de pesquisa. Lefèvre atinge, assim, seu objetivo 
de criar com este trabalho uma matéria de conteúdo" inicial, como fonte de temas para confeç̧ão de hipóteses sobre o sentido do medicamento. Segundo ele, em trabalhos futuros que testem tais hipóteses, se poderá obter "matéria de conteúdo" mais refinada, ou seja, temática mais específica que permitirá definir melhor este campo dinâmico de sentido ligado ao medicamento e, por extensão, à saúde nas sociedades de consumo contemporâneas.

Brani Rosemberg

Departamento de Ciências Biológicas Escola Nacional de Saúde Pública/Fiocruz
Saúde e Sociedade. Augusta Thereza da Alvarenga \& José da Rocha Carvalheiro, (eds.). Publicação da Faculdade de Saúde Pública da Universidade de São Paulo e da Associação Paulista de Saúde Pública: São Paulo, Brasil, 1992, semestral.

Assinaturas: Saude e Sociedade. Avenida Dr. Arnaldo, 715, São Paulo, SP, 01246-904, Brasil.

Queremos saudar e dar boas-vindas a um novo veículo destinado à divulgação e discussão de temas e idéias vinculadas à saúde pública/coletiva.

Foi lançada, em São Paulo, a Revista Saúde e Sociedade, sob a responsabilidade da Associação Paulista de Saúde Pública e Faculdade de Saúde Pública da Universidade de São Paulo. Talvez em função dessa duplicidade, conta com a dupla de editores Augusta Thereza de Alvarenga e José da Rocha Carvalheiro.

A finalidade deste novo periódico, que se propõe a ser bianual, está expressa na contracapa do primeiro número: Saúde e Sociedade é uma revista que tem por finalidade divulgar a produção das diferentes áreas do saber sobre as práticas de saude, visando o desenvolvimento interdisciplinar do campo da saúde pública Destina-se à comunidade de profissionais do campo da saúde, docentes, pesquisadores, especialistas da área da saúde pública/coletiva $e$ de áreas afins.

Pela qualidade e competência dos nomes que compõem a Comissão Editorial e pela amostra de autores e conteúdos dos artigos que aparecem neste primeiro número, estamos pressagiando o nascimento não de mais uma revista, mas sim de uma nova revista em saúde pública/coletiva. E, aqui, adotamos para "nova" o mesmo sentido adotado pela Comissão Editorial: o de inovar.

Aliás, assim se expressa a Comissão Editorial, representada por Aracy Witt de Pinho Spinola (Diretora da Faculdade de Saúde Pública da Universidade de São Paulo) e Álvaro Escrivão Júnior (Presidente da Associação Paulista de Saúde Pública): Saude e Sociedade nasce com o propósito de inovar no campo da saúde pública. Inovar significa, para nós, propiciar espaço para que aflore um novo tipo de reflexão sobre os problemas de saúde pública/coletiva que afetam nosso pais e todo o continente latino-americano. Os problemas, é certo, nem sempre são novos, como é o caso do ressurgir do cólera em nosso continente e em nosso país, mas o modo de pensá-los é necessariamente novo; nisto consiste nosso desafio.

$\mathrm{E}$ em que consiste este modo de pensar que é necessariamente novo? Ainda segundo o ponto de vista da Comissão Editorial, esta inovação está na importância que a mesma confere a uma maior interação entre universidade e serviços de saúde, com vistas à produção de conhecimento, incentivando a divulgação da reflexão sobre as práticas de saúde e estimulando a participação mais ativa dos profisssionais de saúde na criação de um espaço para o debate das mesmas. É, pois, pretensão do novo períodico favorecer a criaçāo de um novo vínculo forte, orgânico e de caráter permanente dos profissionais de sauide pública que trabalham nas universidades com aqueles que atuam nos serviços de saúde, permitindo caracterizar Saúde e Sociedade como uma revista realmente nova.

A proposta fundamental de Saude e Sociedade consiste em: (1) divulgar um tipo de reflexão científica rigorosa, mas de caráter ensaístico; 